\title{
PROLONGED STORAGE OF OYSTER MUSHROOM BY MODIFIED ATMOSPHERE PACKAGING AND LOW TEMPERATURE STORAGE
}

\author{
C.K. ILLEPERUMA* AND K.G.L.R.JAYATHUNGE \\ Department of Food Science \& Technology, Faculty of Agriculture, University of Peradeniya.
}

(Received: 20 February 2003 ; accepted : 29 May 2003)

\begin{abstract}
Oyster mushroom was packaged in $0.015 \mathrm{~mm}$ linear low density polyethylene (LLDPE) in a 3:1 surface area to product weight ratio and stored at $8 \pm 1{ }^{\circ} \mathrm{C}$ and $70 \pm 2 \%$ relative humidity ( $\mathrm{RH}$ ). Effectiveness of magnesium oxide in modifying the in-package gaseous atmosphere and thereby, extending the postharvest life was tested by monitoring the concentrations of oxygen, carbon dioxide, ethanol, weight loss and the ' $L$ ' value of oyster mushroom. The developed modified atmosphere packaging system was compared with commercial packages. In-package oxygen concentrations were 5.5 and $8.5 \%$, carbon dioxide concentrations were 8.1 and $4.5 \%$ and ethanol contents were 53 and $33 \mathrm{ppm}$ in the control and packages containing $3 \mathrm{~g}$ of magnesium oxide, respectively, on day 12 in storage. The ' $L$ ' values of mushroom in the control and packages containing $3 \mathrm{~g}$ of magnesium oxide were 63 and 73 , respectively, on day 12 in storage. Oyster mushroom can be packaged in $0.015 \mathrm{~mm}$ LLDPE in a 3:1 surface area to product weight ratio and stored at $8 \pm 1{ }^{\circ} \mathrm{C}$ and $70 \pm 2 \%$ $\mathrm{RH}$ for 6 days. Further extension of storage life up to 12 days was possible when $3 \mathrm{~g}$ of magnesium oxide was used inside the packages. Polypropylene used in commercial packaging of oyster mushroom was found to be unsuitable.
\end{abstract}

Key words: modified atmosphere storage, Oyster mushroom, packaging

\section{INTRODUCTION}

Oyster mushroom (Pleurotus spp) is popular in Sri Lanka as a vegetable and as an ingredient in soup. However, it is not freely available particularly due to its perishable nature, which limits the storage life to a couple of days. Physiological disorders are the main causes of postharvest losses of mushroom. ${ }^{1}$ These disorders are mainly caused by slow handling of the product, which enhances the opening and darkening of the gills, wilting of the entire structure and brown discoloration of cap and stem. ${ }^{2}$ Storage temperature further enhances the physiological disorders as the rate of biological reactions increase with increase in temperature. ${ }^{3}$ Low temperature storage has been reported to be effective in retarding deterioration and senescence of harvested mushrooms ${ }^{4}$ due to decreased rate of respiration. Storage of mushroom at 0 and $4{ }^{\circ} \mathrm{C}$ has extended the shelf life up to 4 and 2 days, respectively. ${ }^{2}$ Quality of mushroom in terms of colour and microbial spoilage has been reported to be excellent at $0^{\circ} \mathrm{C} .{ }^{4}$ Further improvement of mushroom quality and thereby extended marketable life has been shown when stored at $0{ }^{\circ} \mathrm{C}$ and $95 \%$ Relative Humidity $(\mathrm{RH}) .{ }^{5}$

\footnotetext{
"Corresponding author
} 
Low temperature storage in combination with modified atmosphere packaging (MAP) is reported to extend the postharvest life of vegetables. ${ }^{6}$ The success of MAP is due to the creation and maintenance of an optimal in-package atmosphere, which is determined by respiration rate of the product and permeability of the packaging film to oxygen and carbon dioxide. In Sri Lanka, mushrooms are packaged in polypropylene (PP). However, shelf life of these packages is about 2 days under ambient conditions and about 4 days under low temperature conditions. Condensation of moisture inside these packages and off-colour development are common problems in mushroom packaging, probably due to low permeability of packaging films to water vapour, ${ }^{7}$ oxygen and carbon dioxide. Moisture condensation is further aggravated under the low $\mathrm{RH}$ conditions of refrigerated storage.

Most of the work on mushroom storage has been done on button mushroom (Agaricus bisporus), which is more popular than oyster mushroom in western countries. This study was carried out to develop a MAP system to extend the storage life of oyster mushroom. The effectiveness of magnesium oxide as a carbon dioxide scavenger in extending the postharvest life was also tested.

\section{METHODS AND MATERIALS}

Fresh oyster mushrooms (Pleurotus spp.) of the $2^{\text {nd }}$ flush were harvested from a commercial farm at Haragama in the Kandy district and transported to the laboratory. Mushrooms were sorted by size $(8 \pm 1 \mathrm{~cm}$ diameter $)$ and appearance. Diseased, damaged and extremely large or small mushrooms were discarded to minimize biological variability.

In a previous study, a washing treatment was established, a suitable packaging material was selected and a surface area to product weight ratio for packaging was established for oyster mushroom. ${ }^{8}$ Accordingly, fresh oyster mushrooms were sorted, washed in the washing solution containing $0.5 \%$ calcium chloride and $0.5 \%$ citric acid, air-dried and packaged ( $200 \mathrm{~g}$ per package) in $0.015 \mathrm{~mm}$ linear low-density polyethylene (LLDPE) in a 3:1 surface area to product weight ratio with carbon dioxide scavengers. Magnesium oxide 1, 3 or $5 \mathrm{~g}$ wrapped with muslin cloth was used as a carbon dioxide scavenger in a completely randomised design. A sample without magnesium oxide was used as the control. Twenty-one packages were used for each treatment and for the control. Self-sealing septa were fixed onto the packages to facilitate gas measurements. The packages were heat-sealed and stored at $8 \pm 1{ }^{\circ} \mathrm{C}$ and $70 \pm 2 \% \mathrm{RH}$ for 14 days. In-package concentrations of carbon dioxide and oxygen, ethanol content, colour and weight loss were determined at two-day intervals in triplicate as described below. The data of this experiment were subjected to variance analysis using the SAS package. Treatment means were compared at $\mathrm{p}<0.05$ according to the LSD mean separation procedure. 
Comparison of the experimental and commercial samples: Commercial mushroom packages were prepared using $0.0375 \mathrm{~mm} \mathrm{PP}$, which is used by commercial packaging industries. Mushrooms were washed with $0.5 \%$ calcium chloride and $0.5 \%$ citric acid, air-dried and packaged (200 g per package) in PP in a 3:1 surface area to product weight ratio. Experimental packages were prepared by washing mushrooms ( $200 \mathrm{~g}$ per package) with $0.5 \%$ calcium chloride and $0.5 \%$ citric acid, followed by air drying and packaging in $0.015 \mathrm{~mm}$ LLDPE in a 3:1 surface area to product weight ratio with $3 \mathrm{~g}$ of magnesium oxide. Mushroom packaged in perforated LLDPE $(0.378$ $\mathrm{cm}^{2} / 100 \mathrm{~cm}^{2}$ ) was used as the control. Three samples each of the commercial, experimental and control packages were stored at $8 \pm 1{ }^{\circ} \mathrm{C}$ and $70 \pm 2 \% \mathrm{RH}$ and observed daily for changes in appearance, particularly colour, to have an understanding about the storage life. Three more commercial packages were stored under similar conditions and analysed for in-package concentrations of carbon dioxide, oxygen and acetaldehyde, weight loss and colour on day 6 in storage at $8 \pm 1$ ${ }^{\circ} \mathrm{C}$ and $70 \pm 2 \% \mathrm{RH}$. Results of this experiment were compared with those obtained for three experimental packages stored for 12 days and three control packages stored for 2 days at $8 \pm 1{ }^{\circ} \mathrm{C}$ and $70 \pm 2 \% \mathrm{RH}$. The data of this experiment were subjected to variance analysis using the SAS package. Treatment means were compared at $p<0.05$ according to the LSD mean separation procedure.

Gaseous composition: In-package concentrations of oxygen and carbon dioxide were measured by using a gas chromatograph (Shimadzu, Model GC-14B, Tokyo, Japan). For oxygen measurement, a molecular sieve column, a thermal conductivity detector, helium carrier gas at a flow rate of $40 \mathrm{ml} / \mathrm{min}$, and column, injector and detector temperatures of 50, 90 and $110^{\circ} \mathrm{C}$, respectively, were used. Carbon dioxide was measured using a Poropak Q column, and the conditions were the same as for oxygen.

Acetaldehyde and ethanol contents: Mushroom $(5 \mathrm{~g})$ was homogenized with $5 \mathrm{ml}$ of distilled water using a mortar and pestle. The homogenate was centrifuged at $6000 \mathrm{x} \mathrm{g}$ for $10 \mathrm{~min}$ and $2 \mu \mathrm{l}$ of the supernatant were injected to the gas chromatograph (Shimadzu, Model GC-14B, Tokyo, Japan). Acetaldehyde and ethanol contents were analysed according to the methods of $\mathrm{AOAC}^{9}$ using a Porapak $\mathrm{Q}$ column, a flame ionisation detector, nitrogen carrier gas at a flow rate of $40 \mathrm{ml} / \mathrm{min}$, and column, injector and detector temperatures of 190 and $200{ }^{\circ} \mathrm{C}$, respectively.

Weight loss and colour: Weight loss was determined during storage by monitoring the weight of the contents of the package before and after the storage period. Weight loss was expressed as the percentage loss of weight with respect to the initial weight. Mushroom colour was measured using a Colour Difference Meter (ZE 2000 Nippon Denshuku, Tokyo, Japan). The lightness value (L) was used to evaluate the colour. The measurements were made directly on the cap surface three times on each mushroom. 


\section{RESULTS}

\section{Gaseous composition}

In-package oxygen and carbon dioxide concentrations between the control and packages containing 1,3 and $5 \mathrm{~g}$ of magnesium oxide were significantly different at p $<0.05$ (Figure 1). Oxygen concentration was 4.0, 8.5, 9.9 and $5.5 \%$ in the packages containing 1, 3 and $5 \mathrm{~g}$ of magnesium oxide and the control, respectively, on day 12 in storage. Under similar conditions, carbon dioxide concentration was 7.5, 4.5, 3.0 and $8.1 \%$, respectively (Figure 1). In-package carbon dioxide concentration increased above $5 \%$ after 12 days in all treatments. Oxygen concentration in packages containing 3 and $5 \mathrm{~g}$ of magnesium oxide remained above $5 \%$ up to day 14 in storage and was below $5 \%$ in the control and packages containing $1 \mathrm{~g}$ of magnesium oxide.
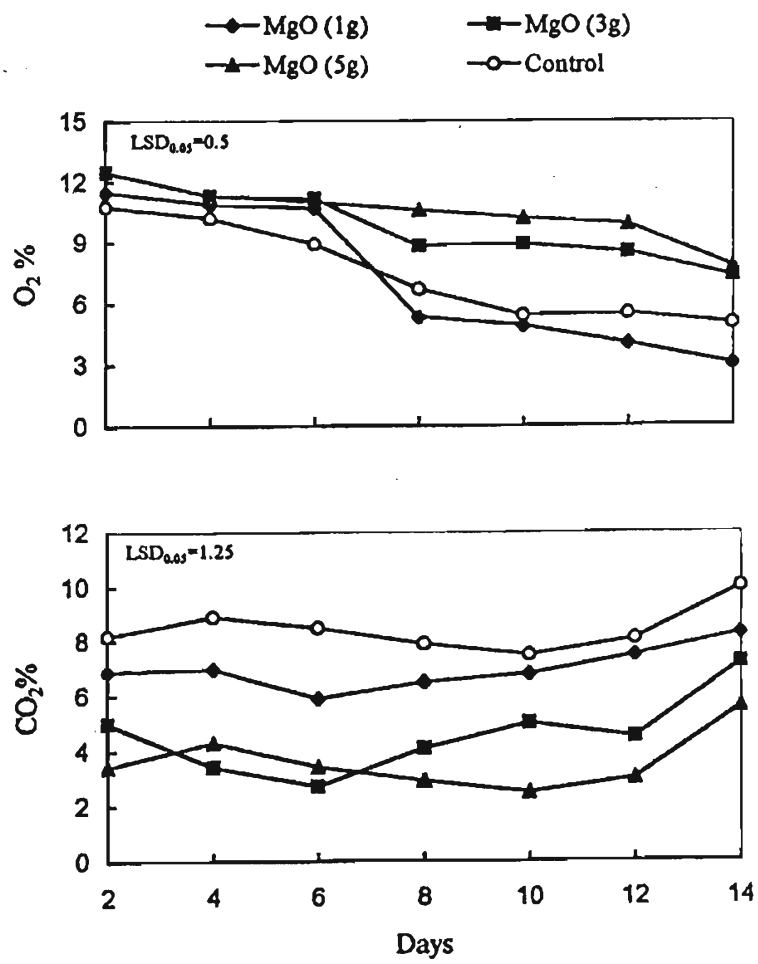

Figure 1: Effect of magnesium oxide as a carbon dioxide absorber on in-package concentrations of carbon dioxide and oxygen of mushroom stored in LLDPE at $8 \pm 1^{\circ} \mathrm{C}$ and $70 \pm 2 \% \mathrm{RH}$.

\section{Weight loss, colour and ethanol content}

Weight loss was about $2.1 \%$ for mushroom in the control and in the packages containing 3 and $5 \mathrm{~g}$ of magnesium oxide on day 12 in storage. Mushrooms in the 
packages containing $1 \mathrm{~g}$ of magnesium oxide showed the lowest weight loss of $1.9 \%$ after 12 days in storage. On day 14, mushroom packaged with $1 \mathrm{~g}$ of magnesium oxide showed $2.1 \%$ weight loss, which was significantly lower than the samples packaged with 3 or $5 \mathrm{~g}$ of magnesium oxide and the control (Figure 2).
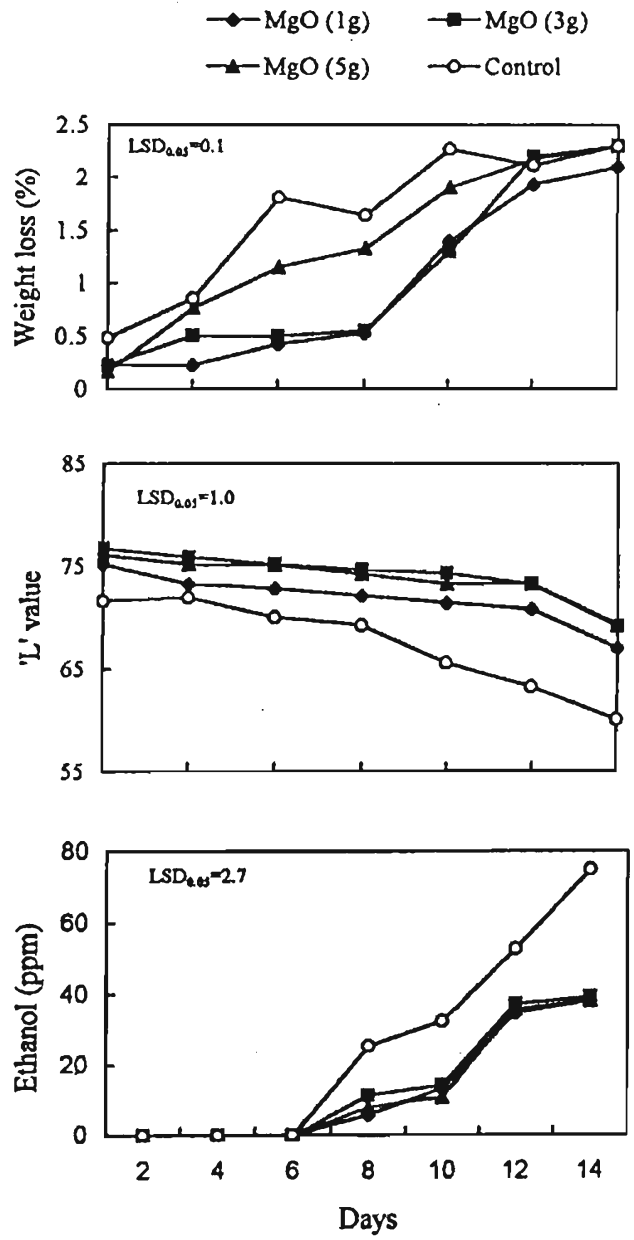

Figure 2: Weight loss, ' $L$ ' value and ethanol content of mushroom as affected by the quantity of magnesium oxide during storage in LLDPE at $8 \pm 1{ }^{\circ} \mathrm{C}$ and $70 \pm 2 \% \mathrm{RH}$.

Lightness of mushroom as indicated by the ' $L$ ' value was $60.0,70.0,71.2$ and 72.3 in the control and in packages containing 1,3 and $5 \mathrm{~g}$ of magnesium oxide, respectively, on day 12 in storage (Figure 2). Mushrooms packaged with 3 and $5 \mathrm{~g}$ of magnesium oxide showed the highest ' $L$ ' values throughout the storage period. The control samples showed the lowest ' $L$ ' value (Figure 2), which was significantly different at $\mathrm{p}<0.05$ from all other treatments. 
There was no production of ethanol in all the samples up to 6 days in storage. Concentration of ethanol increased after day 6 in storage and was significantly higher in the control samples than those packaged with magnesium oxide (Figure 2). On day 12, ethanol concentration of mushroom packaged with 1,3 , and $5 \mathrm{~g}$ of magnesium oxide and in the control, increased to $34.7,37.3,35.7$ and 52.7 ppm, respectively. Ethanol concentration increased further from day 12 to day 14 (Figure 2).

\section{Comparison of the experimental and commercial samples}

In-package oxygen concentration was significantly higher and carbon dioxide concentration was significantly lower in the samples packaged in $0.015 \mathrm{~mm}$ LLDPE than those packaged in $0.0375 \mathrm{~mm}$ PP, the commercial samples, on day 12 and day 6 in storage (Table 1). Mushroom packaged in LLDPE contained significantly lower concentration of acetaldehyde and showed significantly higher ' $L$ ' values than the commercial samples after storage for 12 and 6 days, respectively. However, there was no significant difference in the ' $L$ ' value of samples in $\mathrm{PP}$ and perforated packages. Weight loss of mushrooms in perforated packages was significantly higher than those in LLDPE or PP packages (Table 1).

Table 1: Gaseous composition, chemical and physical parameters of mushroom stored at $8 \pm 1{ }^{\circ} \mathrm{C}$ and $70 \pm 2 \% \mathrm{RH}$ under different packaging conditions.

\begin{tabular}{lcccccc}
\hline $\begin{array}{l}\text { Condition of } \\
\text { packaging }\end{array}$ & $\begin{array}{c}\text { Storage } \\
\text { period } \\
\text { (days) }\end{array}$ & $\mathrm{CO}_{2} \%$ & $\mathrm{O}_{2} \%$ & $\begin{array}{c}\mathrm{CH}_{3} \mathrm{CHO} \\
(\mathrm{ppm})\end{array}$ & $\begin{array}{c}\text { 'L' } \\
\text { value }\end{array}$ & $\begin{array}{c}\text { Weight } \\
\text { loss (\%) }\end{array}$ \\
\hline $\begin{array}{l}\text { Experimental } \\
\text { sample* }\end{array}$ & 12 & $4.50 \mathrm{~b}$ & $8.5 \mathrm{~b}$ & $27.3 \mathrm{~b}$ & $73.3 \mathrm{a}$ & $2.2 \mathrm{~b}$ \\
$\begin{array}{l}\text { Commercial } \\
\text { sample }^{* *}\end{array}$ & 6 & $11.60 \mathrm{a}$ & $3.2 \mathrm{c}$ & $42.0 \mathrm{a}$ & $65.3 \mathrm{~b}$ & $2.0 \mathrm{~b}$ \\
Control $^{* * *}$ & 2 & $0.05 \mathrm{c}$ & $20.8 \mathrm{a}$ & $\mathrm{nd}$ & $63.2 \mathrm{~b}$ & $21.5 \mathrm{a}$ \\
$\mathrm{LSD}_{0.05}$ & & 1.51 & 1.9 & 4.6 & 3.9 & 2.0 \\
\hline
\end{tabular}

- washed with $0.5 \% \mathrm{CA}+0.5 \% \mathrm{CaCl}_{2}$ and packaged in $0.015 \mathrm{~mm} \mathrm{LLDPE}$ with carbon dioxide scavenger (3 $\mathrm{g} \mathrm{MgO}$ ).

* washed with water and packaged in $0.0375 \mathrm{~mm}$ PP.

*** washed with $0.5 \% \mathrm{CA}+0.5 \% \mathrm{CaCl}_{2}$ and packaged in perforated $\left(0.378 \mathrm{~cm}^{2} / 100 \mathrm{~cm}^{2}\right) \mathrm{LLDPE}$ with carbon dioxide scavenger ( $3 \mathrm{~g} \mathrm{MgO}$ ). Each value represents the mean of triplicates and when followed by the same letter within the same column was not significantly different at $p<0.05$.

nd-not detectable 


\section{DISCUSSION}

Decrease in oxygen concentration lower than the tolerable level and increase in carbon dioxide concentration higher than the tolerable level during storage are the major problems of extending the storage life of mushroom by MAP. ${ }^{3}$ Lopez-Briones et al., ${ }^{10}$ reported a minimum tolerable oxygen concentration of 1-2\% while Burton et al., ${ }^{11}$ suggested a minimum tolerable concentration of 3-4 \% for button mushroom. Devece et al..${ }^{12}$ reported a maximum tolerable carbon dioxide concentration of $12 \%$ for button mushroom. However, Lopez-Briones et al. ${ }^{10}$ identified a need to establish in-package oxygen and carbon dioxide concentrations within 5-10\% and 2.5-5\%, respectively, to optimise marketing conditions for button mushroom. ${ }^{10}$ The maximum tolerable concentration of carbon dioxide and minimum tolerable concentration of oxygen for oyster mushroom was found to be different from those reported for button mushroom. Increase in carbon dioxide concentration above $8.5 \%$ and decrease in oxygen concentration below $4.5 \%$ was found to be injurious as reflected by decrease in the ' $\mathrm{L}$ ' value of mushroom in the control and in packages containing $1 \mathrm{~g}$ of magnesium oxide below 70 , the minimum ' $L$ ' value recommended for mushroom. ${ }^{13}$

The 'L'value of all the samples was higher than 70 and there was no detectable levels of ethanol production up to day six in storage regardless of the treatment. This indicates that oyster mushroom can be packaged in 0.015 mm LLDPE in a 3:1 surface area to product weight ratio and stored at $8 \pm 1{ }^{\circ} \mathrm{C}$ and $70 \pm 2 \%$ R.H. for 6 days. Further extension of storage life up to 12 days was possible when 3 or $5 \mathrm{~g}$ of magnesium oxide was used as indicated by the ' $L$ ' values higher than 70 and lower ethanol contents of mushroom in these packages than that of the control. Moreover, mushroom colour was acceptable even on day 12 when packaged in LLDPE with 3 or $5 \mathrm{~g}$ of magnesium oxide, probably due to the ability of magnesium oxide to keep the in-package carbon dioxide concentration below $10 \%$, above which brown colour development was observed in button mushroom. ${ }^{14}$ The ability to extend the postharvest life of oyster mushroom up to 12 days may be due to reduction of respiration rate at low temperature of $8^{\circ} \mathrm{C}$ and modified atmosphere of $8.5 \%$ oxygen and $4.5 \%$ carbon dioxide in LLDPE packages. Reduction of respiration rate by $50 \%$ has been reported for button mushrooms that were stored at $4^{\circ} \mathrm{C}$ for 12 days in MA containers. ${ }^{3}$ Ajlouni ${ }^{15}$ made similar observations when button mushrooms were packaged in linear polystyrene trays overwrapped with PVC films and stored at $12{ }^{\circ} \mathrm{C}$ for 4 days.

Moisture loss by transpiration during storage is another problem as mushrooms lack a protective epidermal structure, as indicated by a $21 \%$ weight loss of mushroom packaged in perforated LLDPE. Moisture loss by diffusion through the film and loss of carbon reserves due to respiration contribute to weight loss of mushroom during storage. ${ }^{16}$ Therefore, selection of a suitable packaging material to reduce the rates of moisture diffusion and respiration is important. Weight loss increased up to about $2 \%$ during storage and there was no significant difference 
between samples packaged with different quantities of magnesium oxide and the control on day 12 in storage. Moreover, there was no difference in the weight loss between the commercial samples packaged in $0.0375 \mathrm{~mm} \mathrm{PP}$ and experimental samples packaged in $0.015 \mathrm{~mm}$ LLDPE with $3 \mathrm{~g}$ of magnesium oxide. However, $0.015 \mathrm{~mm}$ LLDPE was found to be more suitable than $0.0375 \mathrm{~mm}$ PP as indicated by the higher ' $L$ ' value, lower acetaldehyde content and longer shelf life when packaged in the former than in the latter. Moreover, PP was found to be unsuitable for creating a modified atmosphere that was not injurious to mushroom tissues as indicated by higher than $8.5 \%$ carbon dioxide and lower than $4.5 \%$ oxygen in the packages on day 6 in storage. Therefore, packaging of oyster mushroom in 0.015 $\mathrm{mm}$ LLDPE in surface area to product weight ratio of $3: 1$ and storage at $8 \pm 1^{\circ} \mathrm{C}$ and $70 \pm 2 \% \mathrm{RH}$ can be recommended for storage of oyster mushroom.

\section{References}

1 Kannaiyan K. \& Ramasamy K. (1980). A Handbook of Edible Mushrooms. pp.1-50. Royal Off-Set Printers, Delhi.

2 Barden C.L., Beelman R.B., Bartley C.E. \& Schisler L.C. (1990). The Effect of calcium chloride added to the irrigation water on quality and shelf-life of harvested mushrooms. Journal of Food Protection 53 (9): 759-762.

3 Tano K., Arul J., Doyon G. \& Castaigne F. (1999). Atmospheric composition and quality of fresh mushrooms in modified atmosphere packages as affected by storage temperature abuse. Journal of Food Science 64 (6): 1073-1077.

4 Murr D.P. \& Morris L. (1975). Effect of storage temperature on postharvest changes in mushrooms. Journal of American Society Horticultural Science 100 (1): 16-19.

$5 \quad$ Sea Land Services Inc. (1991). Shipping guide for perishables. Sea Land Corporate Marketing, 379, Thornall St. Edison, N. J. 08837.

6 Paull R.E. (1999). Effect of temperature and relative humidity on fresh commodity quality. Postharvest Biology and Technology 15: 263-277.

$7 \quad$ Exama A., Arul J., Lencki R.W., Lee L.Z. \& Toupin C. (1993). Suitability of plastic films for modified atmosphere packaging of fruits and vegetables. Journal of Food Science 58 (6): 1365-1370.

8 Jayathunge K.G.L.R. \& Illeperuma C.K (2001). Extension of postharvest life of oyster mushroom under ambient conditions. Tropical Agricultural Research 13:78-89. 
9 AOAC. (1990). Official Methods of Analysis. Vol. 2. pp 69-81. Association of Official Analytical Chemists, Inc, Virginia.

10 Lopez-Briones G., Varoquauxx P., Bureau G. \& Pascat B. (1993). Modified atmosphere packaging of common mushroom. International Journal of Food Science and Technology 28: 57-68.

11 Burton K.S., Frost C.E. \& Nichols R. (1987). A combination plastic permeable film system for controlling postharvest mushroom quality. Biotechnology Letters 9: 529-534.

12 Devece C., Rodriguez-Lopez J.N., Fenoll L.G., Judela J., Catala J., Reyes E. de I. \& Elliott T.J. (1999). Modified atmosphere storage of the cultivated mushroom Agaricus bisporus. Mushroom Research 8(1): 19-24.

13 Gomley T.R. (1975). Chill storage of mushrooms. Journal of the Science of Food and Agriculture 26: 401-411.

14 Nichols R. \& Hammond B.W. (1973). Storage of mushrooms in pre-packs: the effect of changes in carbon dioxide and oxygen on quality. Journal of the Science of Food and Agriculture 24: 1371-1381.

15 Ajlouni S.O., Beelman R.B., Thompson D.B. \& Mau J.L. (1993). Quality and shelf-life comparison between off-white and white hybrids (U1 and U3) of Agaricus bisporus. Mushroom Research 2 (1): 29-36.

16 Roy S., Anantheswaran R.C. \& Beelman R.B. (1995). Fresh mushroom quality as affected by modified atmosphere packaging. Journal of Food Science 60 (2): 334-340. 